\title{
Patient Preferences for Treating "OFF" Episodes in Parkinson's Disease: A Discrete Choice Experiment
}

\author{
Andrew Thach' \\ Jessie Sutphin ${ }^{2}$ \\ Joshua Coulter ${ }^{2}$ \\ Colton Leach ${ }^{2}$ \\ Eric Pappert ${ }^{3}$ \\ Carol Mansfield (D) ${ }^{2}$ \\ 'Health Economics and Outcomes \\ Research, Sunovion Pharmaceuticals Inc., \\ Marlborough, MA, USA; ${ }^{2}$ Health \\ Preference Assessment, RTI Health \\ Solutions, Research Triangle Park, NC, \\ USA; ${ }^{3}$ Medical Affairs, Sunovion \\ Pharmaceuticals Inc., Marlborough, \\ MA, USA
}

Correspondence: Andrew Thach Health Economics and Outcomes Research, Sunovion Pharmaceuticals Inc., 84 Waterford Dr, Marlborough, MA 01752 , USA

$\mathrm{Tel}+1$ 774-369-7I23

Email andrew.thach@sunovion.com
Introduction: Several on-demand treatments are available for management of "OFF" episodes in patients with Parkinson's disease (PD). We evaluated patients' preferences for features of theoretical on-demand treatment options.

Methods: In a discrete choice experiment, US adults with self-reported PD of $\geq 5$ years, or $<5$ years with "OFF" episodes, taking oral carbidopa/levodopa, selected between pairs of theoretical on-demand treatments that varied by mode of administration (with and without mode-specific adverse events [AEs]), time to FULL "ON," duration of "ON," and out-ofpocket cost for a 30-day supply. Data were analyzed with a random parameters logit model; results were used to calculate relative importance of treatment attributes, preference shares, and willingness to pay.

Results: Among 300 respondents, $98 \%$ had "OFF" episodes. Across the range of attribute levels included in the survey, avoiding $\$ 90$ cost was most important to respondents, followed by a preferable mode of administration with associated AEs and decreasing time to FULL "ON." Duration of "ON" was relatively less important. On average, respondents preferred a theoretical dissolvable sublingual film versus other theoretical treatments with alternative modes of administration. Respondents were willing to pay \$28-\$52 US dollars to switch from least- to morepreferred mode of administration with associated AEs, $\$ 58$ to reach FULL "ON" in 15 versus 60 min, and \$9 to increase duration of FULL “ON" from 1 to $2 \mathrm{~h}$.

Conclusion: Respondents with PD valued lower out-of-pocket cost and a sublingual mode of administration with its associated AEs when choosing an on-demand treatment for "OFF" episodes.

Keywords: apomorphine sublingual film, discrete choice experiment, "OFF" episode, Parkinson's disease, patient preference

\section{Introduction}

Parkinson's disease (PD) is a chronic, progressive, neurodegenerative disorder, with symptoms including tremor, rigidity, bradykinesia, and gait disturbance/postural instability, ${ }^{1}$ that affects approximately 1 million people in the United States (US). ${ }^{2}$ There is no cure for PD, and the disease can affect each person differently, thus requiring treatment options that are tailored to the individual patient. ${ }^{3,4}$ Oral carbidopa/levodopa (CD/LD) is considered the most effective treatment for $\mathrm{PD} ;{ }^{1}$ however, approximately $40 \%$ of patients experience "OFF" episodes after 4-6 years of $\mathrm{CD} / \mathrm{LD}$ treatment, and approximately $70 \%$ of patients experience "OFF" episodes beyond 9 years of $\mathrm{CD} / \mathrm{LD}$ treatment. ${ }^{5}$ An "OFF" episode is defined as a change in a patient's clinical state in which motor and/or nonmotor symptoms 
reappear or worsen. In contrast, an "ON" episode is when a patient responds to medication and has good mobility and motor function. ${ }^{1,6}$

Although treatment with dopamine agonists or other adjunctive therapies (eg, on-extenders) may decrease daily "OFF" time by 0.6 to $2.2 \mathrm{~h}$, patients with PD still experience substantial "OFF" time despite optimized treatments. $^{7-15}$ Moreover, "OFF" episodes may have a significant negative impact on patient quality of life ${ }^{16}$ and can make self-administration of treatment challenging, highlighting the need for on-demand treatments that can rapidly convert patients from "OFF" to FULL "ON" in a manner that can be managed by patients while experiencing symptoms. In the US, currently approved on-demand therapies for the treatment of "OFF" episodes in patients with $\mathrm{PD}$ include apomorphine hydrochloride injection $\left(\mathrm{APOKYN}^{\circledR}\right)$, levodopa inhalation powder $\left(\mathrm{INBRIJA}^{\circledR}\right)$, and apomorphine sublingual film (KYNMOBI $\left.{ }^{\circledR}\right) .{ }^{17-19}$

As the landscape for on-demand treatment of "OFF" episodes evolves, it is important to understand which features patients prefer among the available treatment options. Discrete choice experiment (DCE) studies represent a means to quantify patients' preferences among the features that define a particular treatment class. DCE studies are now widely used to evaluate patients' preferences for treatment features. ${ }^{20}$ In this study, we employed a DCE to quantify patient preferences for features that differentiate theoretical on-demand therapies for treatment of "OFF" episodes.

\section{Methods}

\section{Survey Development}

We developed an online DCE, following best practice, ${ }^{21}$ to evaluate preferences for select attributes of on-demand treatments for "OFF" episodes among a sample of US adults with PD. Respondents chose between alternative theoretical treatment profiles with varying attributes in a series of DCE questions (Table 1; Figure S1).

Selection of the treatment attributes was informed by qualitative research with 15 adults who had received a clinical diagnosis of PD at least 5 years ago. Respondents rated the speed of onset, ability to control symptoms, degree to which the treatment was easy to take when outside the home, adverse events (AEs), mode of administration, duration in which the treatment worked, and cost as the most important features.
Based on this qualitative research, the attributes included in the final survey were mode of administration with mode-specific AEs, time to FULL "ON" (defined in the survey as being back to where symptoms normally were when the respondent's regular, daily PD medicine was working at its best), duration of FULL "ON," and outof-pocket cost for a 30-day supply (Table 1). The levels for mode of administration with AEs, time to FULL "ON," and duration of "ON" were defined using available data on the three approved on-demand products. ${ }^{17-19}$ A wider range of levels that extended below or above the observable range was used to provide more variability and allow for the assessment of thresholds in which the attribute level impacts patient preference. For each mode of administration (inhaled, injected, or dissolvable sublingual film), mode-specific AEs were selected if they were reported among $>5 \%$ of patients in clinical trials. ${ }^{17-19}$ Cost was included as an attribute to facilitate the calculation of willingness to pay (WTP) for improvements in treatment attributes; however, the costs did not necessarily reflect the true costs of currently marketed treatments. Of note, DCE questions did not reflect all attributes and levels of on-demand treatments for "OFF" episodes to avoid overburdening survey respondents with a complex study design.

The survey included patient-friendly descriptions of the attributes, including a picture of each mode of administration, along with brief instructions for administering the treatment. Questions on treatment and symptom experience, opinions about the ease of use of each mode of administration, and demographics were included. The survey included a question about whether the respondent takes a prescription for memory or thinking concerns, and a sensitivity analysis was performed excluding these patients. Another question asked whether patients required assistance using a computer to complete the survey, and the survey prompted those who required assistance to note that all questions should be answered by the patient.

The draft instrument was pretested using 1-on-1 semistructured interviews with 15 patients $18-75$ years of age who had a self-reported physician diagnosis of PD made $\geq 5$ years ago, or made $<5$ years ago but with "OFF" episode experience, and were currently taking oral $\mathrm{CD}$ / LD. The survey instrument was revised based on the pretest interviews to improve readability and reduce cognitive burden.

The combination of attribute levels for the two theoretical on-demand treatments for "OFF" episodes presented 
Table I Attributes and Attribute Levels of Theoretical Treatments for DCE Questions

\begin{tabular}{|l|l|l|}
\hline Attribute & Respondent-Facing Attribute Label & Levels \\
\hline $\begin{array}{l}\text { Mode of administration; adverse } \\
\text { events" }\end{array}$ & $\begin{array}{l}\text { How you take the OFF episode }{ }^{\mathrm{b}} \text { medicine and possible side effect } \\
\text { from the medicine }\end{array}$ & $\begin{array}{l}\text { Inhaled; none } \\
\text { Inhaled; cough or mild respiratory } \\
\text { infection } \\
\text { Injected; none } \\
\text { Injected; injection-site reactions } \\
\text { Dissolvable sublingual film; none } \\
\text { Dissolvable sublingual film; mouth } \\
\text { or lip sores }\end{array}$ \\
\hline Time to FULL "ON"c & How long until you are fully back ON & $\begin{array}{l}15 \text { min } \\
30 \text { min }\end{array}$ \\
60 min
\end{tabular}

Notes: ${ }^{a}$ The mode of administration and mode-specific adverse events were modeled in the experimental design as I attribute with 6 levels. In the DCE questions presented to the respondent, the mode of administration and adverse event were put on 2 rows to make the question easier to read (see Figure SI for an example of a DCE question). "'OFF" episodes were defined in the survey as times when respondents' regular, daily PD medication did not work to control PD symptoms. 'FULL "ON" was defined in the survey as being back to where symptoms normally were when the respondent's regular, daily PD medicine was working at its best.

Abbreviations: DCE, discrete choice experiment; PD, Parkinson's disease.

in each DCE question (example shown in Figure S1) was generated in SAS (SAS Institute, Inc., Cary, NC, USA) using a D-optimal algorithm to construct a fractional factorial experimental design. ${ }^{22,23}$ The design followed good research practices ${ }^{24}$ and was evaluated for level balance and correlation. The full fractional design contained 72 DCE questions that were used to create 8 blocks of 9 DCE questions each. Respondents were randomly assigned to one of the eight blocks of nine questions, the order of which was randomized to avoid ordering effects.

The study was reviewed by the institutional review board at RTI International (Research Triangle Park, NC, USA), who holds a Federal-Wide Assurance (FWA \#3331 effective until November 15, 2023) from the Department of Health and Human Services Office for Human Research Protections, and was determined to be exempt under category 2: Research involving the use of educational tests (cognitive, diagnostic, aptitude, achievement), survey procedures, interview procedures, or observation of public behavior, unless: (i) information obtained is recorded in such a manner that human subjects can be identified, directly or through identifiers linked to the subjects; and (ii) any disclosure of the human subjects' responses outside the research could reasonably place the subjects at risk of criminal or civil liability or be damaging to the subjects' financial standing, employability, or reputation. The study complied with the Declaration of Helsinki. After the survey screening questions, eligible respondents were presented with an Informed Consent Form (ICF) to read on their computer screen, and which provided a contact email to give respondents the ability to ask questions about the research. At the end of the ICF, respondents had to click "Yes" to indicate that they consented to participate in the study, after which they were directed to the survey instrument.

\section{Study Population}

Eligible respondents were US residents, 18-75 years of age, currently taking oral $\mathrm{CD} / \mathrm{LD}$, and had a self-reported physician diagnosis of $\mathrm{PD}$ made $\geq 5$ years ago or made $<5$ years ago but with "OFF" episode experience. Experience with "OFF" episodes was determined with screening questions about whether respondents had ever experienced (1) a time in the morning when their nighttime PD medication had worn off, their PD symptoms reemerged, and they were waiting for their first dose of medicine to start 
working; (2) a time, during the day or night, when their PD medication had worn off too early and their symptoms reemerged, but it was too early to take their next dose of medication; (3) a time when their PD medication took longer to start working than it normally did or when it did not work at all to control their PD symptoms; or (4) unpredictable times in the day, unrelated to when they took their medication, when their PD symptoms suddenly reemerged without warning.

A sample size goal of 300 respondents was targeted. A healthcare research recruiting firm (Global Perspectives, Norwich, England) invited potential respondents via e-mail to take part in an online survey through its online partner panels and other ad hoc sources (ie, recruiters' patient databases, physician referrals, online support groups, and targeted advertising on social media) from September to October 2019.

\section{Statistical Analyses}

Data were analyzed using a random parameters logit (RPL) model, ${ }^{25}$ which related respondents' choices to the differences in attribute levels in each DCE question. RPL models avoid potential estimation bias from unobserved preference heterogeneity among respondents by estimating a distribution of preferences for each preference parameter. ${ }^{26,27}$ Variables for mode of administration with mode-specific AEs, time to FULL "ON," and duration of FULL "ON" were effects-coded categorical variables. Cost was modeled as a continuous linear variable adjusted for the respondent's income. Log-odds parameter estimates resulting from the RPL model were interpreted as preference weights that indicated the relative strength of preferences for each attribute level. The relative importance of treatment attributes was calculated as the difference in preference weights between two attribute levels, and these differences can be compared to each other to determine relative importance. The conditional relative importance of each attribute was also calculated as the difference in preference weights between the most and least preferred levels of each attribute. The sum of the relative attribute importance calculations was scaled to 100 , and the conditional importance of each attribute was a percentage of the total.

Results from the RPL model analysis were also used to predict the probability that an average respondent in the sample would select 1 of 3 treatment profiles over the others (preference shares), where the profiles were defined by specific combinations of attribute levels. ${ }^{26}$ Table S1 presents the two scenarios for three theoretical treatment profiles considered in the analysis of preference shares, which were based on treatments with characteristics similar to apomorphine hydrochloride injection, levodopa inhalation powder, and apomorphine sublingual film, with treatment costs held constant.

Results were also used to calculate respondents' WTP to move to a more preferred mode of administration with and without AEs, a faster time to FULL "ON," and a longer duration of "ON." ${ }^{28}$ WTP values, or monetary equivalents, are an indication of how important a change in an attribute level is to the respondent. Larger WTP values imply a more favorable change, on average, for respondents. A median income of $\$ 87,500$ for the sample was used in the calculations. All costs are reported in US dollars.

\section{Results}

\section{Respondent Characteristics}

Among the 300 respondents, the mean (standard deviation) age was $59(10.7)$ years, $60 \%$ were male, and $83 \%$ were White (Table 2). Most respondents (98\%) experienced "OFF" episodes, with $50 \%$ having at least one "OFF" episode per day and $90 \%$ having more than one "OFF" episode per week. More than one-third of respondents (37\%) had a caregiver who was not a spouse. Overall, $25 \%$ of patients required assistance using a computer to complete the survey. Among the respondent sample, 26\% reported currently taking a prescription medicine for memory or thinking concerns. Results of the sensitivity analysis that excluded respondents who reported currently taking a prescription for memory or thinking concerns were not qualitatively different from the full sample analysis. Therefore, analysis of the preference results was based on the full sample. A theoretical treatment that dissolved under the tongue was rated as the easiest to self-administer, on average, compared with inhaled or injection modes. Most respondents $(79 \%)$ expressed that it was "important" or "very important" to have an on-demand treatment that works well first thing in the morning, and nearly half (45\%) expressed concern with potentially increasing the amount of levodopa they take by using an on-demand treatment that contains additional levodopa to that contained within their maintenance medications.

\section{Preference Weights}

On average, respondents preferred a theoretical dissolvable sublingual film with no AEs over all other modes, regardless 
Table 2 Respondent Characteristics

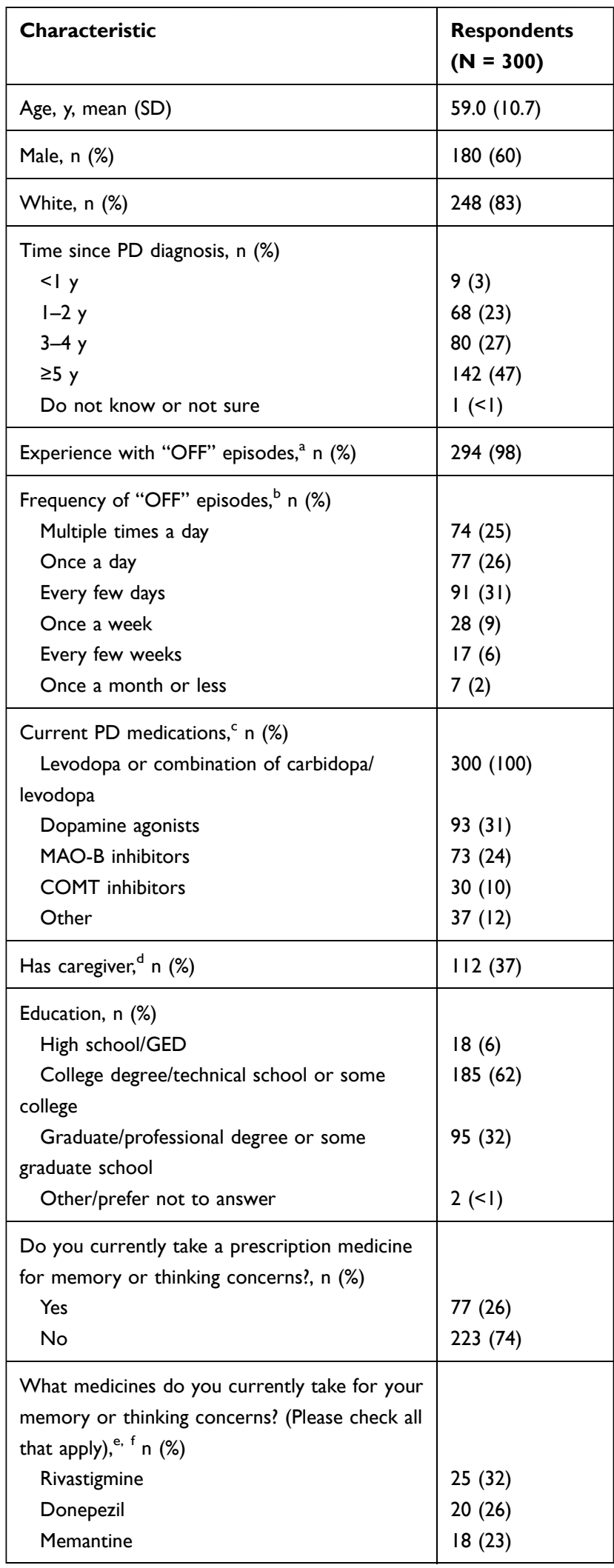

(Continued)
Table 2 (Continued).

\begin{tabular}{|c|c|}
\hline Characteristic & $\begin{array}{l}\text { Respondents } \\
(\mathbf{N}=\mathbf{3 0 0})\end{array}$ \\
\hline $\begin{array}{l}\text { Galantamine } \\
\text { Memantine and donepezil } \\
\text { Other } \\
\text { I do not know the name }\end{array}$ & $\begin{array}{l}12(16) \\
10(13) \\
9(12) \\
7(9)\end{array}$ \\
\hline $\begin{array}{l}\text { On a scale of I to } 5 \text {, where I is very easy and } 5 \\
\text { is very difficult, how difficult do you think it } \\
\text { would be for you to take a medicine that is } \\
\text { injected/inhaled/dissolves under the tongue } \\
\text { using the instructions provided when you are } \\
\text { having an "OFF" episode without help from } \\
\text { someone else? } \\
\text { Injection, mean (SD) } \\
\text { Inhaled medicine, mean (SD) } \\
\text { Dissolvable sublingual film, mean (SD) }\end{array}$ & $\begin{array}{l}3.4(1.2) \\
2.5(1.2) \\
1.9(1.0)\end{array}$ \\
\hline $\begin{array}{l}\text { How important is it to you that an on-demand } \\
\text { treatment works well first thing in the morning?, } \\
\text { n (\%) } \\
\text { Very important } \\
\text { Important } \\
\text { Neither important nor unimportant } \\
\text { Not very important } \\
\text { Not important at all }\end{array}$ & $\begin{array}{l}116(39) \\
122(4 I) \\
40(13) \\
20(7) \\
2(I)\end{array}$ \\
\hline $\begin{array}{l}\text { Are you concerned about increasing the amount } \\
\text { of levodopa you take?, n (\%) } \\
\text { Yes } \\
\text { No } \\
\text { Do not know or not sure }\end{array}$ & $\begin{array}{l}136(45) \\
86(29) \\
78(26)\end{array}$ \\
\hline $\begin{array}{l}\text { Is someone helping you use the computer to } \\
\text { take this survey?, n (\%) } \\
\text { Yes } \\
\text { No }\end{array}$ & $\begin{array}{l}76(25) \\
224(75)\end{array}$ \\
\hline
\end{tabular}

Notes: 'Experience with "OFF" episodes was determined from respondents' answers to 4 screening questions: Have you ever experienced a time in the morning when your nighttime Parkinson's medication dose has worn off, your Parkinson's symptoms reemerge, and you are waiting for your first dose of medicine to start working? Have you ever experienced a time, during the day or night, when your Parkinson's medication has worn off too early and your Parkinson's symptoms reemerge, but it is not time to take your next dose of medication yet? Have you ever experienced a time when your Parkinson's medication takes longer to start working than it normally does or when it does not work at all to control your Parkinson's symptoms? Do you ever experience unpredictable times in the day, unrelated to when you take your medication, when your Parkinson's symptoms suddenly reemerge without warning? "Based on 294 respondents who had experience with "OFF" episodes. 'Respondent responses to this question were distinct from their responses to questions about experience with currently available on-demand treatments of "OFF" episodes. Included full- or part-time caregiver who was not a spouse. ${ }^{\text {eRespondents }}$ could provide multiple responses to this question. 'Based on 77 respondents who were currently taking a prescription medicine for memory or thinking concerns.

Abbreviations: COMT, catechol-O-methyltransferase; GED, General Educational Development; MAO-B, monoamine oxidase-B; PD, Parkinson's disease; SD, standard deviation. 


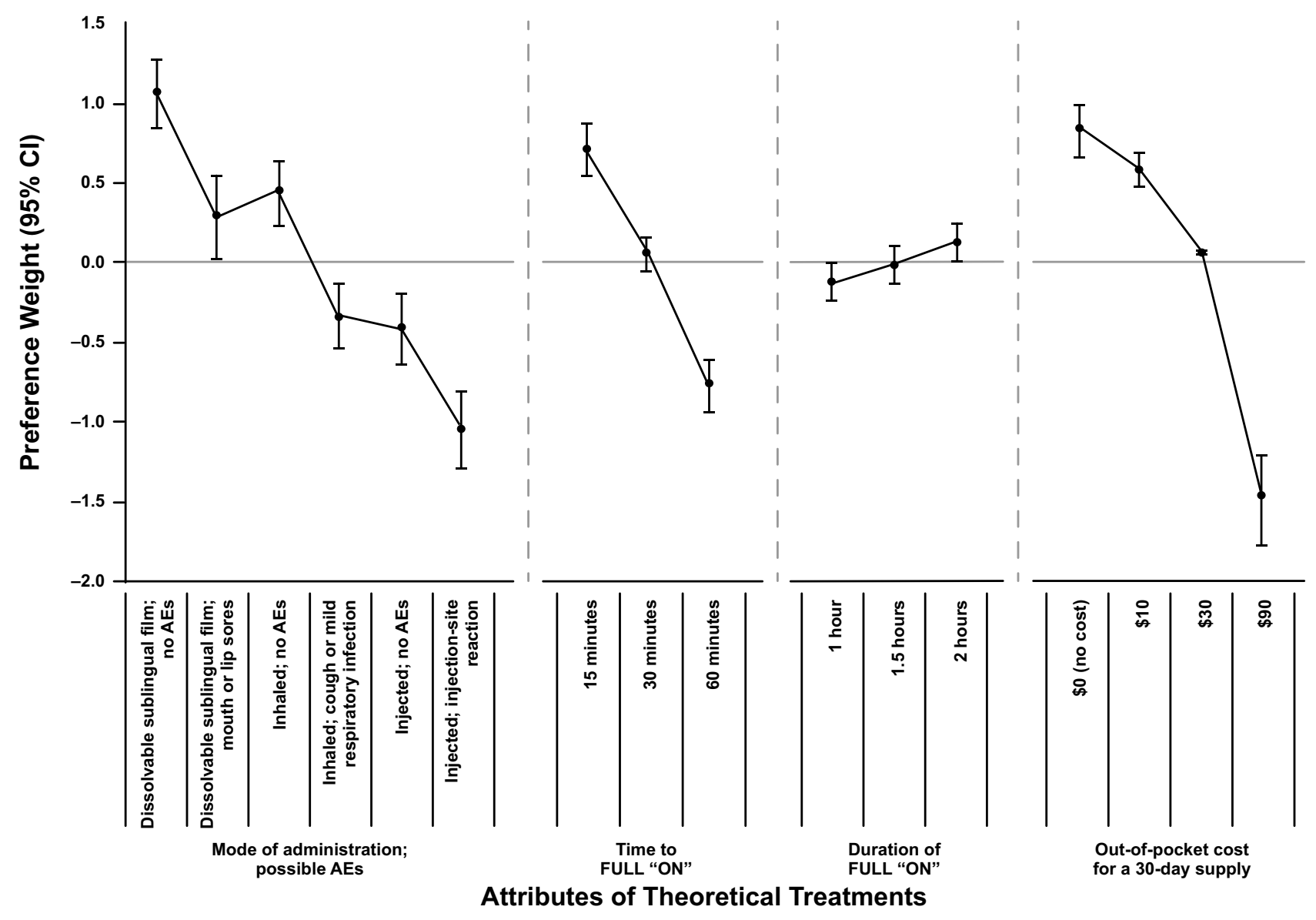

Figure I Normalized mean preference weight estimates for attribute levels of theoretical treatments. The vertical bars surrounding each mean preference weight denote the $95 \%$ confidence intervals $(\mathrm{Cls})$ of the point estimate. The preference weights indicate the ranking of levels within each attribute (ie, a higher preference weight indicates that a level is more preferred).

Abbreviation: $\mathrm{AE}$, adverse event.

of whether the other modes had AEs or not (Figure 1; Table $\underline{\mathrm{S} 2}$. For modes with AEs, respondents preferred a dissolvable sublingual film that may cause mouth or lip sores to an inhaled medicine that may cause a cough or mild respiratory infection. In addition, an inhaled medicine with a risk of cough or mild respiratory infection was preferred over an injected medicine with possible injection-site reactions. On average, respondents also preferred treatments with a rapid onset of effect (treatments that returned them to FULL "ON" more quickly), longer duration ( $2 \mathrm{~h}$ was preferred over $1 \mathrm{~h}$ ), and $\$ 0$ out-of-pocket cost for a 30-day supply.

The size of the difference between two preference weights for an attribute is an indication of the importance of the change to respondents, and this change can be compared with changes in other attributes. Based on the preference weights of each attribute level (Table S2), moving from an inhaled medicine with AEs to a dissolvable sublingual film with AEs was 2.6 times more important than increasing the duration of effect from 1 to $2 \mathrm{~h}$. However, moving from an injected medicine with AEs to a dissolvable sublingual film with AEs was 5.6 times more important than increasing the duration of effect from 1 to $2 \mathrm{~h}$, indicating the high importance of this change in mode of administration.

\section{Conditional Relative Importance}

Across the ranges presented in the survey for theoretical treatments, respondents placed the most importance on the change in out-of-pocket cost per prescription from $\$ 0$ (no cost) to $\$ 90$ (scaled relative importance [95\% confidence interval], 37.5 [30.6, 44.4]) and the change in mode of administration from an injection with possible injectionsite reactions to a dissolvable sublingual film with no AEs (34.4 [28.3, 40.5]; Figure S2). A theoretical treatment that reduced the time to FULL "ON" from 60 to 15 min was the next most important change $(24.2[19.3,29.0])$. The 

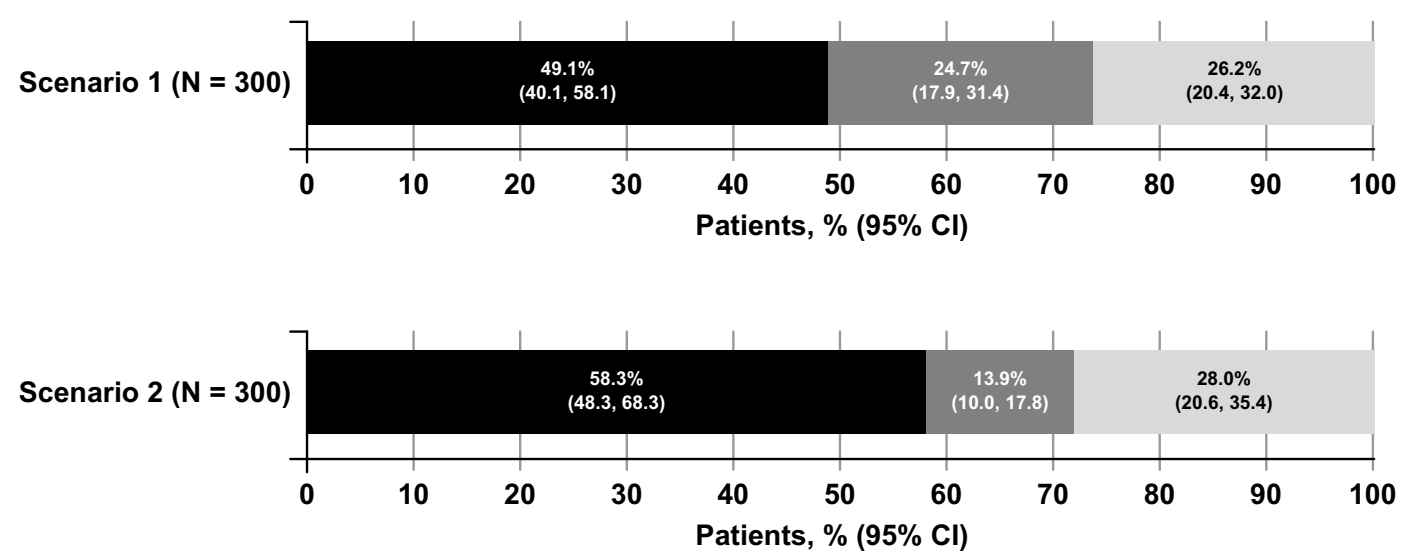

Theoretical treatment A (dissolvable sublingual film)
Theoretical treatment B (injected)
Theoretical treatment C (inhaled)

Figure 2 Preference share analysis. Results from the discrete choice experiment were used to predict the probability that the average respondent would choose a theoretical on-demand treatment for "OFF" episodes based on 2 different scenarios of 3 theoretical treatments, as presented in Table SI. Theoretical treatment A is a dissolvable sublingual film with possible mouth or lip sores, theoretical treatment $B$ is an injection with possible injection-site reactions, and theoretical treatment $C$ is an inhaled drug with possible cough or mild respiratory infection. In scenario I, theoretical treatment B works faster (I5 min) to reach FULL "ON"; in scenario 2, all 3 theoretical treatments reach FULL "ON" in $30 \mathrm{~min}$. In scenario 2, theoretical treatment A has a longer duration of "ON" (I.5 h); in scenario I, all 3 theoretical treatments have the same duration of "ON" (I h). In both scenarios, out-of-pocket cost for a 30 -day supply is held constant at $\$ 30$ for each treatment.

Abbreviation: $\mathrm{Cl}$, confidence interval.

change in duration of "ON" from 1 to $2 \mathrm{~h}$ was relatively less important for a theoretical treatment compared with the ranges of other attributes presented in the survey (3.9 $[0.6,7.2])$.

\section{Preference Shares}

Results from the DCE analysis were used to predict the probability that the average respondent in the sample would choose each of the three theoretical treatments for "OFF" episodes similar to those presented in scenarios 1 and 2 (Table S1). Predicted preference share analyses demonstrated that respondents were more likely, on average, to select a theoretical dissolvable sublingual film (Treatment A, 58.3\%) compared with a theoretical injected drug (Treatment B, 13.9\%) or a theoretical inhaled drug (Treatment C, 28.0\%) when all 3 treatments had the same theoretical out-of-pocket cost for a 30-day supply (\$30; Figure 2, scenario 2). This trend held true even when the scenario dictated that the injected drug worked faster (15 min to reach FULL "ON") than the dissolvable sublingual film or inhaled drug (30 min to reach FULL "ON"; Figure 2, scenario 1).

\section{Willingness to Pay}

Respondents' average WTP to move from the least preferred mode of administration (injection with possible injection-site reactions) to the most preferred mode of administration (dissolvable sublingual film with no AEs) was $\$ 83$ (Table

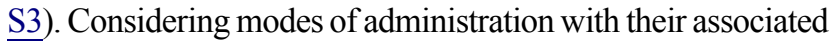
AEs, and starting from an injection with possible injection-site reactions, respondents were willing to pay, on average, \$52 for a dissolvable sublingual film with possible mouth or lip sores and \$28 for an inhaled medicine with possible cough or mild respiratory infection. Starting from an inhaled medicine with possible cough or mild respiratory infection, respondents were willing to pay $\$ 24$ for a dissolvable sublingual film with possible mouth or lip sores. Respondents' average WTP for a theoretical treatment that decreased the time to FULL "ON" from $1 \mathrm{~h}$ to $15 \mathrm{~min}$ was $\$ 58$.

On average, respondents in the sample were not willing to pay to change from a dissolvable sublingual film with possible mouth or lip sores to an inhaled medicine with no AEs, nor were they willing to pay to change from an inhaled medicine with possible cough or mild respiratory infection to an injected medicine with no AEs. While respondents were willing to pay $\$ 9$ for a theoretical treatment that increased the duration of FULL "ON" from 1 to 2 $\mathrm{h}$, they were not willing to pay to increase the duration of FULL “ON" from 1 to $1.5 \mathrm{~h}$ or from 1.5 to $2 \mathrm{~h}$ (Table S3).

\section{Discussion}

This study quantified the preferences of patients with PD for the features of theoretical on-demand treatments for "OFF" episodes to better understand patients' treatment 
characteristic priorities. Overall, respondents preferred treatments in which the mode of administration was a dissolvable sublingual film, with rapid onset, longer duration of effect, and low cost. Respondents preferred a theoretical dissolvable sublingual film with no AEs over all other modes, regardless of whether the other modes had AEs or not. The least preferred mode was a theoretical injection with possible injection-site reactions. Respondents preferred theoretical treatments that returned them to FULL "ON" in 15 min over treatments that took longer (30 min or $1 \mathrm{~h}$ ). Respondents also preferred theoretical treatments that had a $\$ 0$ out-of-pocket cost more than treatments with any greater cost. Respondents preferred theoretical treatments that controlled symptoms for $2 \mathrm{~h}$ over those that controlled symptoms for only $1 \mathrm{~h}$.

Across the ranges presented in the survey, respondents placed the most importance on the change in out-of-pocket cost per prescription from $\$ 0$ (no cost) to $\$ 90$ and change in mode of administration from an injection with possible injection-site reactions to a dissolvable sublingual film with no AEs. Change in time to FULL "ON" from 60 to $15 \mathrm{~min}$ was the next most important attribute for a theoretical treatment. Change in duration of FULL "ON" from 1 to $2 \mathrm{~h}$ was relatively less important compared with the ranges of other attributes presented in the survey. From the preference results, we created two scenarios of three theoretical treatments and predicted the probability that an average respondent in the sample would select one of the treatments. On average, respondents were more likely to select a theoretical dissolvable sublingual film versus other theoretical treatments with alternative modes of administration.

While prior preference research has shown that patients with PD value increased duration of "ON" time with $\mathrm{PD}$ therapy, ${ }^{29,30}$ to our knowledge, this represents the first patient preference study targeted toward on-demand treatments for "OFF" episodes. A key finding is that patients find rapid onset of effect to be an important treatment attribute. Prior research suggests that some patients may be hesitant to receive daily injections (ie, fearful of needles) and may have trouble assembling administration devices while "OFF." $31-33$ Based on these prior findings, we hypothesize that the comparative ease of administration of a theoretical sublingual film may have appealed to respondents; however, the survey did not ask for an explanation of respondents' preferences.
Some limitations common to DCE studies must be acknowledged. The survey presents theoretical scenarios to respondents, and decisions made in the survey may not fully predict decisions made in a clinical setting where other considerations may arise. A recent study by de Bekker-Grob et al compared the actual decisions that went into getting an influenza vaccine to the predictions from a DCE survey and found a high degree of concordance. ${ }^{34}$ Research in another neurological disorder, relapsing/remitting multiple sclerosis, used the results from a DCE survey to compare actual prescribing behavior in the UK with prescribing patterns based on the preferences estimated in the DCE. ${ }^{35}$ Overall, the model predicted that patients might have better health outcomes if prescribing patterns were based on patient preferences. There are a number of reasons why the predictions based on a DCE might be different from actual treatment usage, a phenomenon attributed not only to the treatment characteristics put forth in the DCE, but also prescription and reimbursement policies, physician preferences, and brand marketing. ${ }^{35,36}$ In addition, the attributes and levels included in the DCE questions in this study do not reflect all attributes and levels of on-demand treatments for "OFF" episodes currently available or in development. In particular, AE attributes related only to mode of administration and the risks of these events vary with initial versus chronic exposure. Other potential AEs associated with on-demand treatments were not considered. Furthermore, AE attributes did not take into account severity, frequency, or duration of events to avoid overburdening survey respondents with a complex study design. Another limitation is that the levels used for time to FULL "ON" and duration of FULL "ON" were estimates and may not necessarily represent those observed in clinical practice. Furthermore, the preferences for 2 of the 3 theoretical treatments (dissolvable sublingual film and injected) do not account for the need to titrate to an optimized dose, nor the potential for AEs during the titration period and the potential use of concomitant medications to prevent or treat these AEs. The respondents were recruited through opt-in panels of individuals who choose to participate in research and other ad hoc recruiting channels, and the preferences of the sample may not be representative of the broader population of patients with PD. Finally, the online setting of the survey could have impacted the generalizability of the results. 


\section{Conclusion}

Given the attributes and levels presented in the survey, respondents preferred a theoretical dissolvable sublingual film, with rapid onset of effect, longer duration of effect, and low out-of-pocket cost. Physicians should work with their patients to assess the need for an on-demand treatment for "OFF" episodes that fits their patients' lifestyles and circumstances.

\section{Acknowledgments}

The authors acknowledge the patients who participated in this research, as well as their families and caregivers. The authors acknowledge Kimberly Moon of RTI Health Solutions for overall project management. Medical writing and editorial support were provided by RTI Health Solutions and The Lockwood Group (Stamford, CT, USA) and were supported by funding from Sunovion Pharmaceuticals Inc. This research was presented in part at the International Society for Pharmacoeconomics and Outcomes Research (ISPOR) Virtual Congress, May 18-20, 2020, and the International Congress of Parkinson's Disease and Movement Disorders (MDS) Virtual Congress, September 12-16, 2020.

\section{Author Contributions}

AT, JS, JC, and CM contributed to the study concept and design. All authors participated in data acquisition, analysis, or interpretation. JS, JC, CL, and CM performed the statistical analysis. All authors were involved in the drafting and critical review of the manuscript, agreed on the target journal, approved the final version, and agreed to be accountable for all aspects of the work.

\section{Funding}

This study was conducted under a research contract between RTI Health Solutions (Research Triangle Park, NC, USA) and Sunovion Pharmaceuticals Inc. (Marlborough, MA, USA). The study was supported by funding from Sunovion Pharmaceuticals Inc.

\section{Disclosure}

AT and EP are salaried employees of Sunovion Pharmaceuticals Inc. JS was a salaried employee of RTI Health Solutions when the study was conducted and is now affiliated with Duke Clinical Research Institute, Duke University, Durham, NC, USA. JC, CL, and CM are salaried employees of RTI Health Solutions. The authors report no other conflicts of interest in this work.

\section{References}

1. Olanow CW, Stern MB, Sethi K. The scientific and clinical basis for the treatment of Parkinson disease (2009). Neurology. 2009;72(21 suppl 4):S1-S136. doi:10.1212/WNL.0b013e3181a1d44c

2. Marras C, Beck JC, Bower JH, et al. Prevalence of Parkinson's disease across North America. NPJ Parkinsons Dis. 2018;4:21. doi:10.1038/s41531-018-0058-0

3. Armstrong MJ, Okun MS. Diagnosis and treatment of Parkinson disease: a review. JAMA. 2020;323(6):548-560. doi:10.1001/ jama.2019.22360

4. Titova N, Chaudhuri KR. Personalized medicine in Parkinson's disease: time to be precise. Mov Disord. 2017;32(8):1147-1154. doi: $10.1002 / \mathrm{mds} .27027$

5. Ahlskog JE, Muenter MD. Frequency of levodopa-related dyskinesias and motor fluctuations as estimated from the cumulative literature. Mov Disord. 2001;16(3):448-458. doi:10.1002/mds.1090

6. Chou KL, Stacy M, Simuni T, et al. The spectrum of "off" in Parkinson's disease: what have we learned over 40 years? Parkinsonism Relat Disord. 2018;51:9-16. doi:10.1016/j. parkreldis.2018.02.001

7. Pahwa R, Stacy MA, Factor SA, et al. Ropinirole 24-hour prolonged release: randomized, controlled study in advanced Parkinson disease. Neurology. 2007;68(14):1108-1115. doi:10.1212/01. wnl.0000258660.74391.c1

8. Lieberman A, Ranhosky A, Korts D. Clinical evaluation of pramipexole in advanced Parkinson's disease: results of a double-blind, placebo-controlled, parallel-group study. Neurology. 1997;49 (1):162-168. doi:10.1212/WNL.49.1.162

9. Waters CH, Sethi KD, Hauser RA, Molho E, Bertoni JM; Zydis Selegiline Study Group. Zydis selegiline reduces off time in Parkinson's disease patients with motor fluctuations: a 3-month, randomized, placebo-controlled study. Mov Disord. 2004;19 (4):426-432. doi:10.1002/mds.20036

10. Rascol O, Brooks DJ, Melamed E, et al. Rasagiline as an adjunct to levodopa in patients with Parkinson's disease and motor fluctuations (LARGO, Lasting effect in Adjunct therapy with Rasagiline Given Once daily, study): a randomised, double-blind, parallel-group trial. Lancet. 2005;365(9463):947-954. doi:10.1016/S0140-6736(05)71083-7

11. Rajput AH, Martin W, Saint-Hilaire MH, Dorflinger E, Pedder S. Tolcapone improves motor function in parkinsonian patients with the "wearing-off" phenomenon: a double-blind, placebo-controlled, multicenter trial. Neurology. 1997;49(4):1066-1071. doi:10.1212/ WNL.49.4.1066

12. Elmer LW, Juncos JL, Singer C, et al. Pooled analyses of phase III studies of ADS-5102 (amantadine) extended-release capsules for dyskinesia in Parkinson's disease. CNS Drugs. 2018;32(4):387-398. doi:10.1007/s40263-018-0498-4

13. Hauser RA, Hsu A, Kell S, et al. Extended-release carbidopalevodopa (IPX066) compared with immediate-release carbidopalevodopa in patients with Parkinson's disease and motor fluctuations: a phase 3 randomised, double-blind trial. Lancet Neurol. 2013;12 (4):346-356. doi:10.1016/S1474-4422(13)70025-5

14. LeWitt PA, Guttman M, Tetrud JW, et al. Adenosine A2A receptor antagonist istradefylline (KW-6002) reduces "off" time in Parkinson's disease: a double-blind, randomized, multicenter clinical trial (6002-US-005). Ann Neurol. 2008;63(3):295-302. doi:10.1002/ ana. 21315

15. Vijiaratnam N, Foltynie T. Therapeutic strategies to treat or prevent off episodes in adults with Parkinson's disease. Drugs. 2020;80 (8):775-796. doi:10.1007/s40265-020-01310-2 
16. Chapuis S, Ouchchane L, Metz O, Gerbaud L, Durif F. Impact of the motor complications of Parkinson's disease on the quality of life. Mov Disord. 2005;20(2):224-230. doi:10.1002/mds.20279

17. APOKYN ${ }^{\circledR}$ (apomorphine hydrochloride injection) [prescribing information]. Louisville, KY: US WorldMeds, LLC; 2020.

18. INBRIJA ${ }^{\circledR}$ (levodopa inhalation powder) [prescribing information]. Ardsley, NY: Acorda Therapeutics, Inc; 2019.

19. $\mathrm{KYNMOBI}^{\circledR}$ (apomorphine hydrochloride) sublingual film [prescribing information]. Marlborough, MA: Sunovion Pharmaceuticals Inc; 2020.

20. Soekhai V, de Bekker-Grob EW, Ellis AR, Vass CM. Discrete choice experiments in health economics: past, present and future. Pharmacoeconomics. 2019;37(2):201-226. doi:10.1007/s40273-0180734-2

21. Bridges JF, Hauber AB, Marshall D, et al. Conjoint analysis applications in health - a checklist: a report of the ISPOR Good Research Practices for Conjoint Analysis Task Force. Value Health. 2011;14 (4):403-413. doi:10.1016/j.jval.2010.11.013

22. Kuhfeld WF, Tobias RD, Garratt M. Efficient experimental design with marketing research applications. J Marketing Res. 1994;31 (4):545-557. doi:10.1177/002224379403100408

23. Kuhfeld WF. Marketing Research Methods in SAS: Experimental Design, Choice, Conjoint, and Graphical Techniques. Cary, NC: SAS Institute Inc.; 2010.

24. Johnson FR, Lancsar E, Marshall D, et al. Constructing experimental designs for discrete-choice experiments: report of the ISPOR Conjoint Analysis Experimental Design Good Research Practices Task Force. Value Health. 2013;16(1):3-13. doi:10.1016/j. jval.2012.08.2223

25. Hauber AB, Gonzalez JM, Groothuis-Oudshoorn CG, et al. Statistical methods for the analysis of discrete choice experiments: a report of the ISPOR Conjoint Analysis Good Research Practices Task Force. Value Health. 2016;19(4):300-315. doi:10.1016/j.jval.2016.04.004

26. Train K. Discrete Choice Methods with Simulation. Cambridge, UK: Cambridge University Press; 2009.

27. Train K, Sonnier G. Mixed logit with bounded distributions of correlated partworks. In: Scarpa R, Alberini A, editors. Application of Simulation Methods in Environmental and Resource Economics. Boston: Kluwer Academic Publishers; 2005:117-134.
28. Ozdemir S, Johnson FR, Hauber AB. Hypothetical bias, cheap talk, and stated willingness to pay for health care. J Health Econ. 2009;28 (4):894-901. doi:10.1016/j.jhealeco.2009.04.004

29. Marshall T, Pugh A, Fairchild A, Hass S. Patient preferences for device-aided treatments indicated for advanced Parkinson disease. Value Health. 2017;20(10):1383-1393. doi:10.1016/j. jval.2017.06.001

30. Kerr C, Lloyd EJ, Kosmas CE, et al. Health-related quality of life in Parkinson's: impact of 'off' time and stated treatment preferences. Qual Life Res. 2016;25(6):1505-1515. doi:10.1007/s11136-0151187-0

31. Bhidayasiri R, Chaudhuri KR, LeWitt P, Martin A, Boonpang K, van Laar T. Effective delivery of apomorphine in the management of Parkinson disease: practical considerations for clinicians and Parkinson nurses. Clin Neuropharmacol. 2015;38(3):89-103. doi:10.1097/WNF.0000000000000082

32. Bowron A. Practical considerations in the use of apomorphine injectable. Neurology. 2004;62(suppl 4):S32-S36. doi:10.1212/ WNL.62.6_suppl_4.S32

33. Manson AJ, Turner K, Lees AJ. Apomorphine monotherapy in the treatment of refractory motor complications of Parkinson's disease: long-term follow-up study of 64 patients. Mov Disord. 2002;17 (6):1235-1241. doi:10.1002/mds.10281

34. de Bekker-Grob EW, Donkers B, Bliemer MCJ, Veldwijk J, Swait JD. Can healthcare choice be predicted using stated preference data? Soc Sci Med. 2020;246:112736. doi:10.1016/j. socscimed.2019.112736

35. van Eijndhoven E, Brauer M, Kee R, et al. Modeling the impact of patient treatment preference on health outcomes in relapsing-remitting multiple sclerosis. $J$ Med Econ. 2020;23 (5):474-483. doi:10.1080/13696998.2019.1711100

36. Jonker MF, Donkers B, Goossens LMA, et al. Summarizing patient preferences for the competitive landscape of multiple sclerosis treatment options. Med Decis Making. 2020;40(2):198-211. doi:10.1177/ 0272989X19897944
Patient Preference and Adherence

\section{Publish your work in this journal}

Patient Preference and Adherence is an international, peer-reviewed, open access journal that focusing on the growing importance of patient preference and adherence throughout the therapeutic continuum. Patient satisfaction, acceptability, quality of life, compliance, persistence and their role in developing new therapeutic modalities and compounds to optimize clinical outcomes for existing disease states are major areas of interest for the journal. This journal has been accepted for indexing on PubMed Central. The manuscript management system is completely online and includes a very quick and fair peer-review system, which is all easy to use. Visit http:// www.dovepress.com/testimonials.php to read real quotes from published authors. 